\title{
Trinitrotoluene: assessment of occupational absorption during manufacture of explosives
}

\author{
B H WOOLLEN, ${ }^{1}$ M G HALL, ${ }^{1}$ R CRAIG, ${ }^{2}$ AND G T STEEL ${ }^{1}$
}

From the Central Toxicology Laboratory, ${ }^{1}$ Imperial Chemical Industries plc, Alderley Park, Macclesfield, Cheshire, and Medical Department, ${ }^{2}$ Nobel's Explosives Company, Ardeer Works, Stevenston, Ayrshire, UK

ABSTRACT Trinitrotoluene (TNT) absorption was assessed in groups of workers at two explosives factories by measuring the urinary concentrations of dinitroaminotoluene (DNAT) metabolites. DNAT was detected in most of the urine samples analysed and for postshift samples the mean (SD) concentration was $9 \cdot 7(7 \cdot 9) \mathrm{mg} / \mathrm{l}($ range $0 \cdot 1-44 \mathrm{mg} / \mathrm{l}(\mathrm{n}=219))$. Individual workers showed substantial day to day variations in DNAT concentrations in postshift urine samples, but on a group basis the concentrations remained fairly constant throughout the working week. Preshift urine samples taken at the beginning of a working week showed low concentrations of DNAT which initially suggested that the elimination of TNT metabolites is fairly rapid. A survey carried out of preshift and postshift urine samples collected from a group of workers for a full working week showed wide variations in the rate of clearance of TNT metabolites from the body and in some cases higher concentrations of metabolites were seen in the samples taken the morning after exposure. When urine samples were collected from the same group of workers after 17 days away from the workplace DNAT was still detectable in samples from eight of the nine subjects, indicating that a proportion of TNT or its metabolites is slowly excreted. When five subjects were monitored more intensively during two workshifts TNT was shown to be absorbed rapidly during the exposure period. In most cases the highest concentrations were seen in the postshift urine samples but significant proportions were still present in samples taken the morning after exposure. Atmospheric levels of TNT were found to be too low to account for the observed excretion of DNAT and dermal uptake rather than inhalation appears to be the major route of absorption.

2,4,6-Trinitrotoluene (TNT) assumed importance as a principal constituent of many explosives in 1902. It was generally believed to be non-toxic until it was recognised in 1915 that TNT was the cause of 50 fatal cases of jaundice. Many deaths from aplastic anaemia and toxic hepatitis were reported in TNT workers up to the $1950 \mathrm{~s},{ }^{1}$ but with improved industrial practices there have been few recent reports of serious health problems relating to the use of TNT.

The recognition of the toxic potential of TNT and its widespread use has led to many publications on the effects of repeated exposure and overexposure. A comprehensive review on the occupational health and safety aspects of TNT was carried out for the US Army. ${ }^{1}$ The principal target organs are the liver and cardiovascular and nervous systems. In 1976 repeated exposure to TNT below the then threshold limit value

Accepted 4 November 1985 of $1.5 \mathrm{mg} / \mathrm{m}^{3}$ was shown to produce raised levels of certain hepatic enzymes ${ }^{2}$; it is reported that haematological effects have been seen at levels as low as $0.2 \mathrm{mg} / \mathrm{m}^{3} .^{3}$ In response to this new information the threshold limit value for TNT was lowered to 0.5 $\mathrm{mg} / \mathrm{m}^{3}$. $^{4}$

In the United Kingdom TNT is imported by ICI and used in the production of explosive charges. In recent years atmospheric monitoring has been carried out in ICI factories to ensure compliance with the TLV of $0.5 \mathrm{mg} / \mathrm{m}^{3}$. In addition, regular health checks have been made for signs of cyanosis or other ill effects, but none which could be directly related to exposure to TNT has been identified. Since TNT is known to be absorbed through the skin, however, it was thought that atmospheric monitoring for TNT dust might not be the best way of assessing its potential or actual absorption. It was therefore decided to investigate the degree of absorption of TNT in exposed workers using biological monitoring tech- 
Process 1

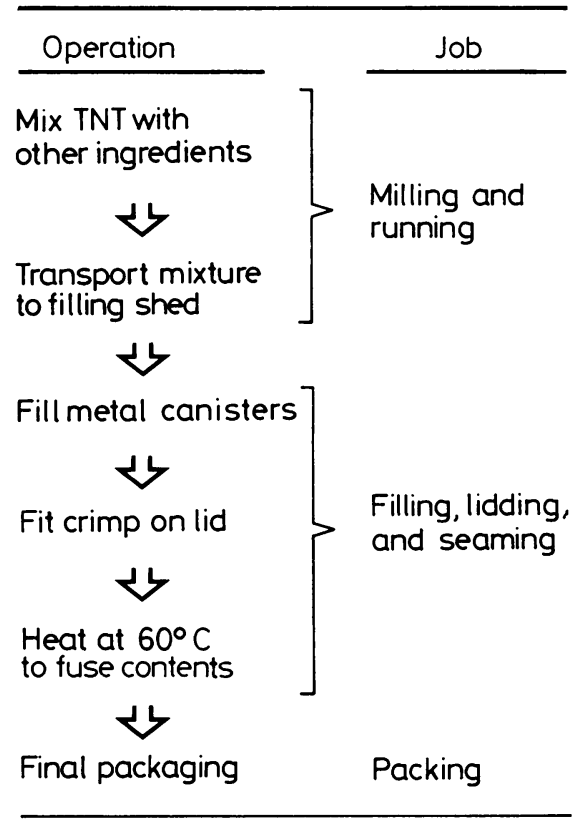

Fig 1 Outline of production processes.

niques and to correlate this with the results of atmospheric monitoring.

Existing information on the metabolism of TNT in experimental animals and man, and on the assessment of absorption in man, dates back to the $1940 \mathrm{~s}^{5-8}$ The main conclusions were that TNT is readily absorbed through the respiratory and gastrointestinal tracts and to a lesser extent through the skin. The major metabolites which have been identified in experimental animals are the various positional isomers of diaminonitrotoluene, dinitrohydroxylaminotoluene, and dinitroaminotoluene (DNAT). In man, however, the major known urinary metabolites identified by Lemberg and Callaghan are the dinitroaminotoluenes [2,6-dinitro-4-aminotoluene (2,6-DNAT) and 2,4-dinitro-6-aminotoluene (2,4-DNAT)]. ${ }^{7}$

It was decided to use the concentrations of the two isomers of DNAT in urine to assess the absorption of TNT. Two colorimetric methods have been developed for measuring DNAT in urine from TNT workers $^{910}$ but neither is specific for DNAT, and there are potential interferences from other aromatic amines, including some common drugs. A specific gas chromatographic method was therefore developed to determine 2,4-DNAT and 2,6-DNAT in urine samples from exposed workers. Since this method was developed details of a similar procedure have been published by another group. ${ }^{11}$

\section{Materials and methods}

\section{DESCRIPTION OF THE PRODUCTION \\ PROCESSES}

Two slightly different processes were investigated and these are summarised in fig 1 . In both, TNT flakes are incorporated into an explosive mixture at an inclusion level of approximately $30 \%$. The mixture is packed into either cardboard tubes or metal canisters that are sealed before packing and despatch. The two main jobs at both locations are "milling" the explosive mixture and "filling" the cartridges. Other jobs include transporting the mixture to the filling shed ("running" or "service waiting"), wax dipping of cardboard cartridges ("dipping"), "packing" the finished products, and "coordinating" the work programme. Women are employed in the filling and packing areas whereas men are employed in all stages of the processes.

\section{STUDY POPULATIONS}

Process 1

The exposed group comprised 17 men and eight women: 15 workers were engaged in tasks in the filling 
area, eight in milling and running, and two in coordinating. During the period of the survey a three shift system was operating (8 hours a shift) for five days a week with some weekend working.

\section{Process 2}

The exposed group comprised eight men and five women: two were mixing, four were filling and crimping, and seven were carrying out other tasks in the factory including maintenance work, engine driving, and general cleaning. A day shift system was operated for five days a week.

\section{Atmospheric monitoring}

Static sampling involved the use of open face glass fibre filters and personal sampling was carried out using charcoal adsorption tubes. TNT was desorbed from collection materials using ethanol and measured by gas chromatography.

\section{STUDY DESIGN}

\section{Study 1 (process 1 )}

Concentrations of 2,4-DNAT + 2,6-DNAT (total DNAT) were measured in spot urine samples taken before starting work at the beginning of the week and thereafter at the end of each daily shift for two separate weeks. Atmospheric monitoring was carried out during the second week of the study.

\section{Study 2 (process 1)}

The time course for the excretion of total DNAT was investigated in five workers during two workshifts at the end of a working week. Two men were engaged in milling and three women worked in the filling department. Urine samples were collected as separate voidings during the working day, during non-working periods, and at least once daily over the weekend. Atmospheric monitoring was carried out during the second workshift.
Study 3 (process 2)

Preshift and postshift urine samples were collected from 13 workers for a full working week, during the weekend, and on the following Monday morning. Atmospheric monitoring was carried out in the middle of the working week.

As a follow up to assess the longer term excretion of TNT or its metabolites in the body, urine samples were collected from nine of the 13 workers before starting work on a Monday morning immediately after a 17 day holiday period.

\section{COLLECTION OF URINE SAMPLES}

Urine samples were collected at either the works medical centre (process 1 ) or the administrative centre (process 2). Subsamples (about $50 \mathrm{ml}$ ) were transferred to plastic bottles, sodium azide was added as a preservative, and the samples were stored at $4^{\circ} \mathrm{C}$ before analysis. Urine creatinine concentration was determined using standard procedures.

\section{ANALYSIS OF URINE SAMPLES}

2,4-DNAT and 2,6-DNAT were measured by gas chromatography with electron capture detection after acid hydrolysis to release bound DNAT. Aliquots of urine $(5 \mathrm{ml})$ were acidified with concentrated hydrochloric acid $(0.5 \mathrm{ml})$ in a screw cap culture tube and heated at $100^{\circ} \mathrm{C}$ for 30 minutes. After cooling, diethyl ether $(5 \mathrm{ml})$ was added and the tubes were vortex mixed for 10 minutes and then centrifuged $(2000 \mathrm{rpm})$ for 10 minutes. An aliquot of the ether extract $(1 \mathrm{ml})$ was transferred to a clean tube and reduced to dryness using a stream of nitrogen. The residue was dissolved in $2 \mathrm{ml}$ of ethyl acetate containing the pesticide p, $\mathrm{p}^{\prime}$-DDE $(0 \cdot 1 \mu \mathrm{g} / \mathrm{ml})$ as an internal standard.

Gas chromatography was carried out using a $2 \mathrm{~m}$ $\times 2 \mathrm{~mm}$ id glass column packed with $3 \% \mathrm{OV}-1701$ on base treated Chromosorb W-AW 80-100 mesh installed in a Varian 6000 gas chromatograph

Table 1 Results of atmospheric sampling

\begin{tabular}{|c|c|c|c|c|}
\hline Study & Process & Type of sample & Operation & $T N T m g / m^{3}$ \\
\hline $\begin{array}{l}1 \\
1 \\
1 \\
2 \\
2 \\
2 \\
2 \\
3 \\
3 \\
3 \\
3 \\
3 \\
3 \\
3\end{array}$ & $\begin{array}{l}1 \\
1 \\
1 \\
1 \\
1 \\
1 \\
1 \\
2 \\
2 \\
2 \\
2 \\
2 \\
2 \\
2\end{array}$ & $\begin{array}{l}\text { Personal } \\
\text { Personal } \\
\text { Static } \\
\text { Personal } \\
\text { Personal } \\
\text { Static } \\
\text { Static } \\
\text { Personal } \\
\text { Personal } \\
\text { Personal } \\
\text { Personal } \\
\text { Static } \\
\text { Static } \\
\text { Static }\end{array}$ & $\begin{array}{l}\text { Milling } \\
\text { Filling } \\
\text { Milling } \\
\text { Milling } \\
\text { Filling } \\
\text { Milling } \\
\text { Filling } \\
\text { Milling } \\
\text { Filling } \\
\text { Crimping } \\
\text { Packing } \\
\text { Milling } \\
\text { Filling } \\
\text { Packing }\end{array}$ & $\begin{array}{l}<0.01,<0.01,0.29 \\
<0.01,<0.01,<0.01,<0.01 \\
5.73,1.21,0.18,0.64,0.12 \\
<0.01 \\
<0.01 \\
0.27 \\
2.53 \\
0.71 \\
0.22 \\
0.39 \\
0.05 \\
0.30 \\
0.02 \\
0.06\end{array}$ \\
\hline
\end{tabular}


equipped with a ${ }^{63} \mathrm{Ni}$ electron capture detector. Conditions were column temperature $240^{\circ} \mathrm{C}$, injector $275^{\circ} \mathrm{C}$, detector $300^{\circ} \mathrm{C}$, carrier gas nitrogen at 30 $\mathrm{ml} / \mathrm{min}$. Retention times were $\mathrm{p}, \mathrm{p}^{\prime}$-DDE (1.2 mins), 2,6-DNAT ( $1.7 \mathrm{mins})$, and 2,4-DNAT (2.1 mins). Since these studies were carried out we have found that a $25 \mathrm{~m} \times 0.32 \mathrm{~mm}$ fused silica capillary column coated with a 1 micron film of BP-10 bonded phase (Scientific Glass Engineering) gives improved chromatographic performance for DNAT analysis.

Standard curves were prepared by spiking control urine to give 2,6-DNAT concentrations within the range $0.05-1.0 \mathrm{mg} / \mathrm{l}$ and unknowns were processed with spiked control samples. The peak area ratio for 2,6-DNAT/DDE was calculated for each spiked urine extract and plotted against the concentration $(\mathrm{mg} / \mathrm{l})$ in the spiked urine. The peak area ratios for 2,6-DNAT/DDE and 2,4-DNAT/DDE were then calculated for the unknowns and the concentrations present were evaluated from the standard curve. Since a reference sample of 2,4-DNAT was not available at the time the work was carried out, its detector response was assumed to be the same as 2,6-DNAT. This has now been confirmed to be the case for an authentic sample of 2,4-DNAT. Sample extracts whose area ratio fell outside the calibration range were diluted with internal standard solution before reanalysis. The limit of determination for DNAT in urine was about $0.01 \mathrm{mg} / \mathrm{l}$.

\section{Results}

\section{STUDY CONDUCT}

Some urine samples were lost due to absence from work or because workers forgot to provide the samples, but the overall compliance with the sampling schedules was greater than $70 \%$ in all the studies.

\section{ATMOSPHERIC CONCENTRATIONS OF TNT}

The results of the atmospheric analyses are summarised in table 1 . For process 1 , the concentrations of TNT detected by personal sampling were, with one exception, below the limit of detection. When TNT was detected in the milling area the concentration was below the recommended limt of $0.5 \mathrm{mg} / \mathrm{m}^{3} .{ }^{12}$ The mean concentration of TNT detected by static sampling was $1.36 \mathrm{mg} / \mathrm{m}^{3}$ in the milling area (range $0.12-5 \cdot 7)$ and $2.53 \mathrm{mg} / \mathrm{m}^{3}$ in the filling area. It should

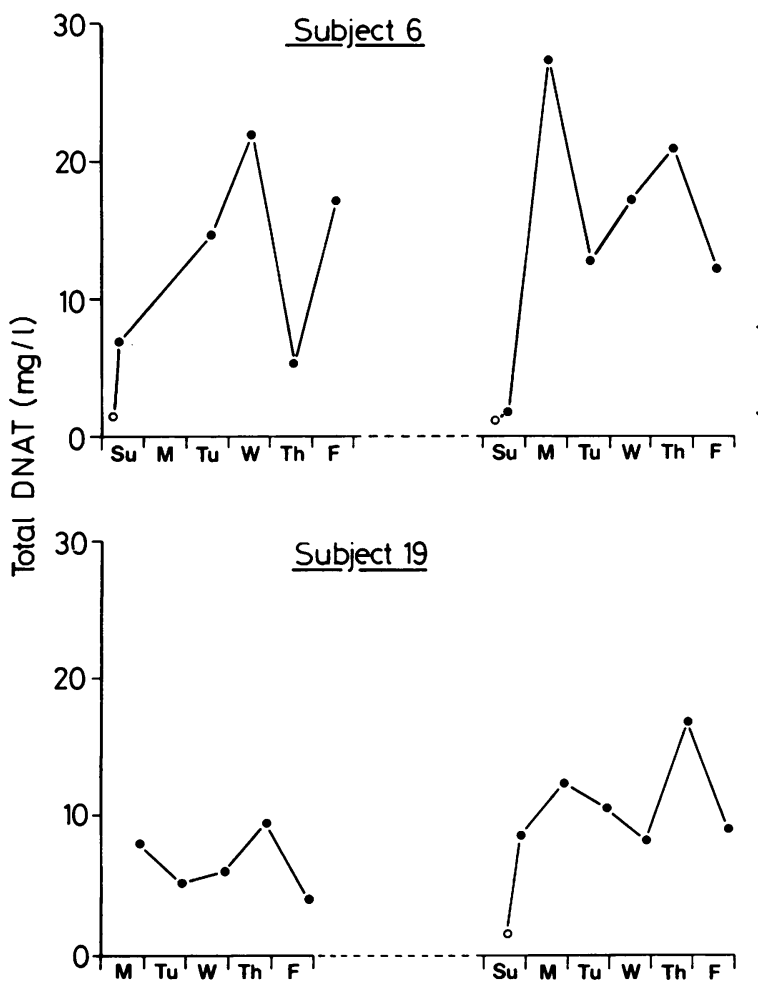

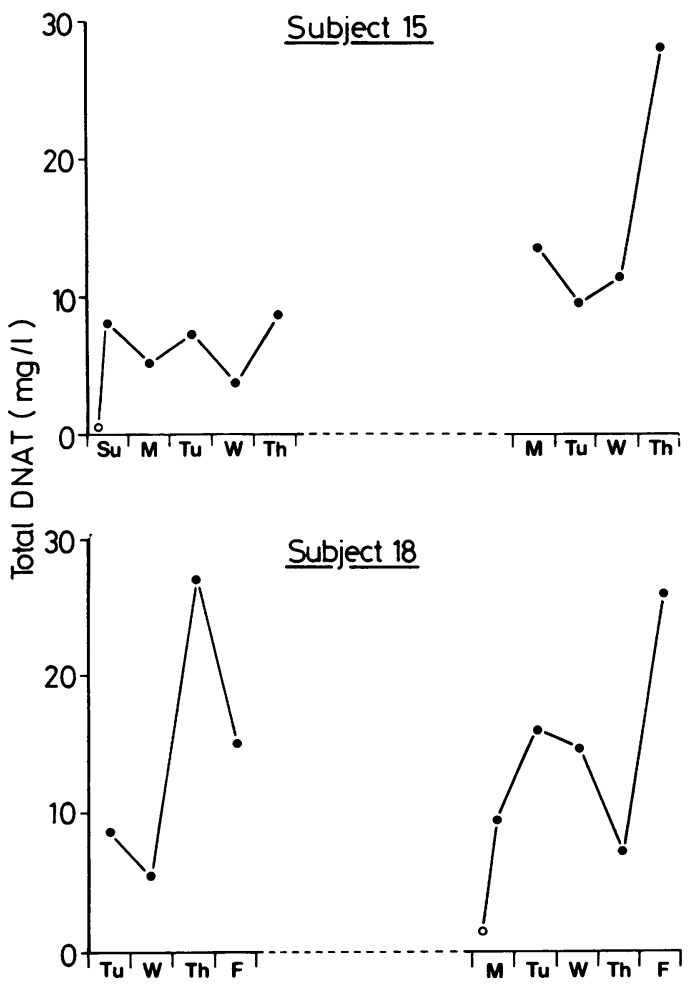

Fig 2 Study 1: total DNAT concentrations in urine for four subjects during two separate one week periods. 


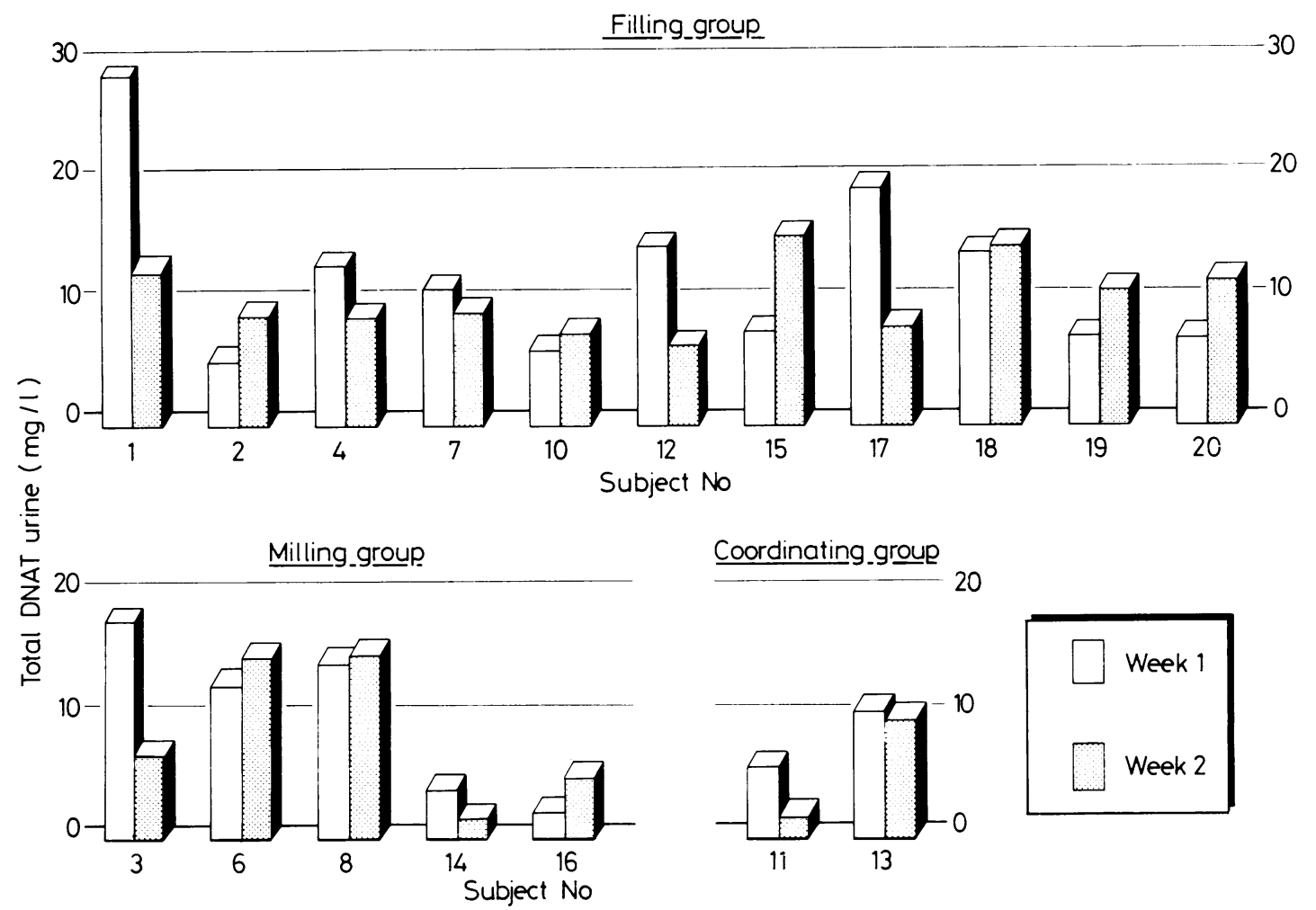

Fig 3 Study 1: weekly mean total DNAT concentrations in urine for 18 subjects for two separate one week periods.

be emphasised that the static sampling devices were positioned close to the points where TNT dust was generated.

For process 2 the mean concentration of TNT detected by personal sampling was $0.34 \mathrm{mg} / \mathrm{m}^{3}$ (range 0.05-0.71). Atmospheric concentrations detected by static sampling ranged from 0.02 to $0.30 \mathrm{mg} / \mathrm{m}^{3}$. For both personal and static samples the highest concentrations were found in the milling area.

\section{BIOLOGICAL MONITORING}

Study 1

DNAT was detected in almost all the postshift urine samples examined and the mean (SD) concentration was $10(8 \cdot 3) \mathrm{mg} / \mathrm{l}$. When individual workers were followed up throughout the working week, total DNAT concentrations varied considerably from day to day (fig 2). To take a broader view, the weekly mean total DNAT concentrations were calculated for 18 individuals for the two separate one week periods. It is apparent (fig 3) that for most of the workers the weekly mean total DNAT concentrations were similar for the two weeks studied and that some individ- uals were excreting consistently higher concentrations of DNAT than other workers. Some subjects, however, showed appreciably different concentrations between weeks 1 and 2 .

When the weekly mean (SD) total DNAT concentrations for the milling group as a whole $(13(8.4) \mathrm{mg} / \mathrm{l}$ in week 1 and $9 \cdot 1(6 \cdot 1) \mathrm{mg} / \mathrm{l}$ in week 2$)$ were compared with those of the filling group $(13(7 \cdot 5) \mathrm{mg} / \mathrm{l}$ in week 1 and $11(3.0) \mathrm{mg} / \mathrm{l}$ in week 2$)$ there was no significant difference $(\mathrm{p}<0 \cdot 1)$.

The total DNAT results for this study were corrected both for specific gravity and creatinine concentration to compensate for different urine volumes. The effect of these corrections is illustrated in fig 4 and it is apparent that the profiles are qualitatively similar after correction. All DNAT concentrations mentioned subsequently refer to uncorrected values.

Our work has confirmed earlier findings that only a small proportion of DNAT is present in urine as a free amine and that the remainder is present in an acid labile bound form. ${ }^{5}$ Some of the properties of bound DNAT are similar to those displayed by the $\mathrm{N}$ glucuronide conjugate of other aromatic amines, ${ }^{13}$ 

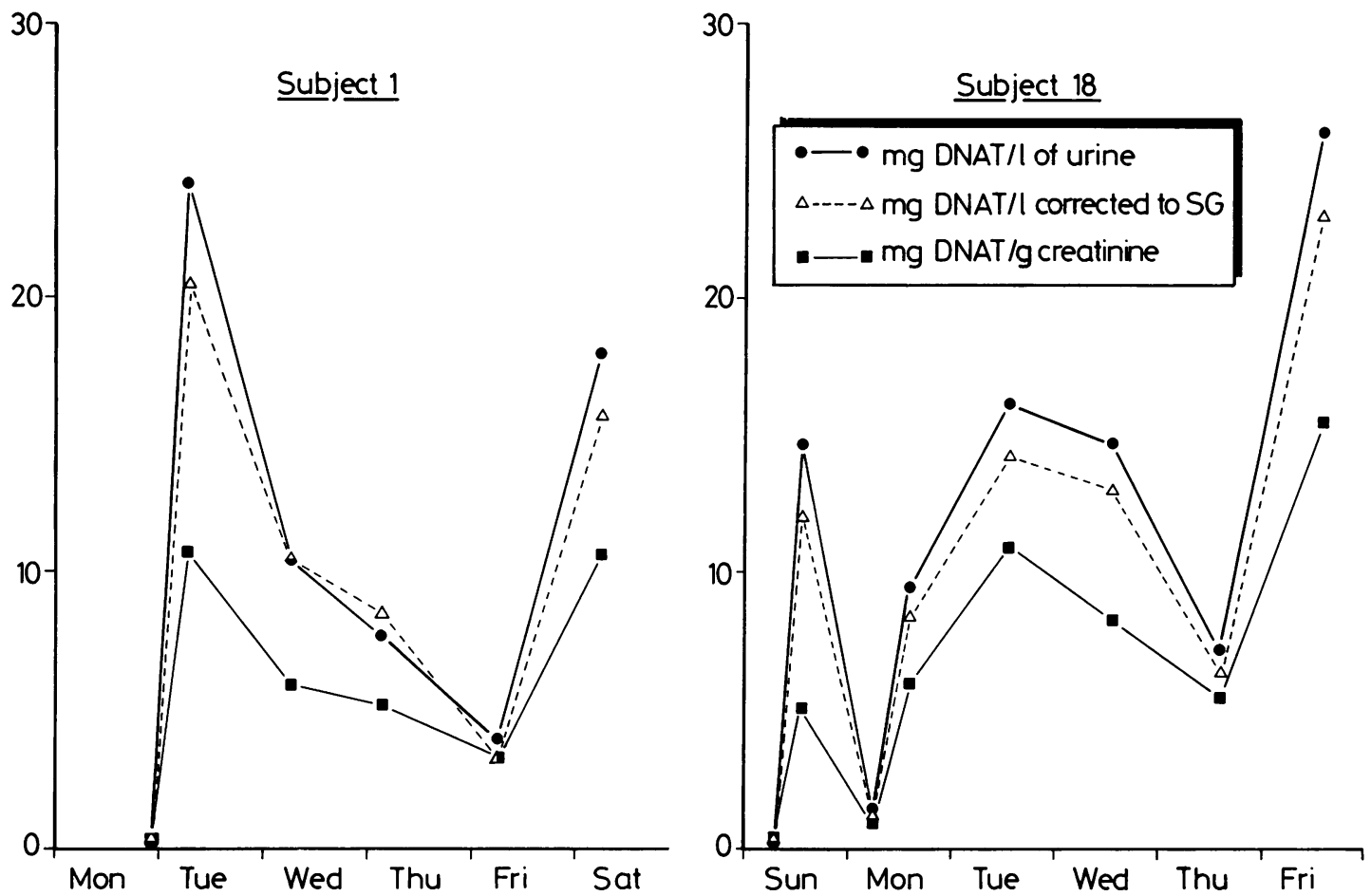

Fig 4 Study 1: effect of correction for urine dilution on the excretion profiles of total DNAT for two individuals.

but attempts to characterise bound DNAT further in this laboratory have so far been unsuccessful.

\section{Study 2}

This study provided further information about the excretion of DNAT after TNT exposure (table 2). All subjects had a relatively low concentration of DNAT in urine on the Sunday morning 36 hours after the last exposure. The intensive sampling carried out during the last two days of the working week (Thursday and Friday), however, showed that although most subjects excreted the highest concentration of total DNAT within a few hours of the end of a shift, considerable amounts were still present in about two thirds of the samples taken on the morning after exposure.

Table 2 Study 2: total DNAT concentrations in urine in $\mathrm{mg} / \mathrm{l}$ ( $\mathrm{mg} / \mathrm{g}$ creatinine). (Figures given in parentheses have been corrected to creatinine excretion)

\begin{tabular}{|c|c|c|c|c|c|}
\hline \multirow[b]{2}{*}{ Time } & \multicolumn{5}{|l|}{ Subject } \\
\hline & (Woman) & (Woman) & (Woman) & (Man) & (Man) \\
\hline $\begin{array}{l}\text { Thursday: } \\
\text { Before shift } \\
\text { Midshift } \\
\text { Postshift } \\
\text { Late evening }\end{array}$ & $\begin{array}{c}6 \cdot 6(3 \cdot 1) \\
6 \cdot 6(4 \cdot 8) \\
21(13) \\
0 \cdot 77(3 \cdot 7)\end{array}$ & $\begin{array}{l}3 \cdot 6(2 \cdot 2) \\
\text { NS } \\
22(11) \\
11(7 \cdot 2)\end{array}$ & $\begin{array}{l}2 \cdot 7(2 \cdot 1) \\
4 \cdot 3(4 \cdot 0) \\
4 \cdot 5(9 \cdot 4) \\
1 \cdot 4(4 \cdot 5)\end{array}$ & $\begin{array}{l}0.24(0.25) \\
1.6(1 \cdot 5) \\
\text { NS } \\
9 \cdot 6(7 \cdot 5)\end{array}$ & $\begin{array}{l}0.10(0.09) \\
5 \cdot 8(2 \cdot 6) \\
3.6(9.0) \\
9.4(3 \cdot 2)\end{array}$ \\
\hline $\begin{array}{l}\text { Friday: } \\
\text { Before shift } \\
\text { Midshift } \\
\text { Postshift } \\
\text { Late evening }\end{array}$ & $\begin{array}{l}4 \cdot 7(2 \cdot 7) \\
4 \cdot 4(2 \cdot 1) \\
17(7 \cdot 1) \\
\text { NS }\end{array}$ & $\begin{array}{l}8 \cdot 3(5 \cdot 2) \\
7 \cdot 5(4 \cdot 2) \\
\mathrm{NS} \\
1 \cdot 7(0 \cdot 9)\end{array}$ & $\begin{array}{l}3 \cdot 7(3 \cdot 7) \\
2 \cdot 8(3 \cdot 2) \\
0 \cdot 58(1 \cdot 5) \\
4 \cdot 4(2 \cdot 6)\end{array}$ & $\begin{array}{l}3 \cdot 5(2 \cdot 3) \\
0 \cdot 93(0 \cdot 89) \\
13(6 \cdot 5) \\
\text { NS }\end{array}$ & $\begin{array}{c}4 \cdot 4(2 \cdot 2) \\
12(4 \cdot 5) \\
6 \cdot 9(5 \cdot 9) \\
4 \cdot 4(2 \cdot 7)\end{array}$ \\
\hline $\begin{array}{l}\text { Saturday: } \\
\text { Morning }\end{array}$ & $3 \cdot 2(1.9)$ & $2.9(1.6)$ & $0 \cdot 10(0 \cdot 16)$ & $1.4(0.8)$ & $1 \cdot 5(1 \cdot 1)$ \\
\hline $\begin{array}{l}\text { Sunday: } \\
\text { Morning }\end{array}$ & NS & $0.42(0.20)$ & $0.51(0.37)$ & $0.41(0.16)$ & $0.37(0.27)$ \\
\hline
\end{tabular}

NS = No sample.

Saturday and Sunday were non-working days. 
Table 3 Study 3: total DNAT concentrations in urine ( $\mathrm{mg} / \mathrm{l})$ and atmospheric levels of TNT

\begin{tabular}{|c|c|c|c|c|c|c|c|c|c|c|c|c|c|c|c|c|c|c|c|}
\hline $\begin{array}{l}\text { Ind } \\
\text { No }\end{array}$ & Sex & $J o b$ & $\begin{array}{l}\text { Atmospheric } \\
T N T \\
\left(\mathrm{mg} / \mathrm{m}^{3}\right)^{*}\end{array}$ & Mon 1 & Mon 2 & Tue 1 & Tue 2 & Wed 1 & Wed 2 & Thu 1 & Thu 2 & Fri I & Fri 2 & $\begin{array}{l}\text { Mean } \\
\text { pre- } \\
\text { shift }\end{array}$ & $\begin{array}{l}\text { Mean } \\
\text { post- } \\
\text { shift }\end{array}$ & Sat & Sun & Mon 1 & $\begin{array}{l}\text { After } \\
\text { holiday } \dagger \\
\text { Mon }\end{array}$ \\
\hline $\begin{array}{l}26 \\
27 \\
28 \\
29 \\
30 \\
31 \\
32 \\
33 \\
34 \\
35 \\
36 \\
37 \\
38 \\
38\end{array}$ & $\begin{array}{l}\mathbf{M} \\
\mathbf{M} \\
\mathbf{F} \\
\mathbf{F} \\
\mathbf{F} \\
\mathbf{F} \\
\mathbf{F} \\
\mathbf{M} \\
\mathbf{M} \\
\mathbf{M} \\
\mathbf{M} \\
\mathbf{M} \\
\mathbf{M}\end{array}$ & $\begin{array}{l}\text { Mixer } \\
\text { Mixer } \\
\text { F\&C } \\
\text { F\&C } \\
\text { F\&C } \\
\text { F\&C } \\
\text { Packing } \\
\text { SW } \\
\text { SW } \\
\text { Loco } \\
\text { Loco } \\
\text { Cleaner } \\
\text { Fitter }\end{array}$ & $\begin{array}{l}0.71 \\
0.71 \\
0.39 \\
= \\
\overline{0.22} \\
0.05 \\
= \\
= \\
= \\
-\end{array}$ & $\begin{array}{r}0.11 \\
0.77 \\
0.18 \\
0.59 \\
0.43 \\
1.29 \\
0.25 \\
<0.10 \\
-\quad \\
0.11 \\
0.23 \\
1.14 \\
<0.10\end{array}$ & $\begin{array}{c}6 \cdot 64 \\
5 \cdot 65 \\
4 \cdot 88 \\
9 \cdot 44 \\
30 \cdot 3 \\
0.38 \\
7 \cdot 36 \\
6 \cdot 38 \\
-2.37 \\
11 \cdot 1 \\
2 \cdot 33 \\
0 \cdot 57\end{array}$ & $\begin{array}{l}1.51 \\
1.76 \\
2 \cdot 13 \\
2 \cdot 16 \\
2.28 \\
1.51 \\
8.59 \\
- \\
- \\
1.84 \\
4.03 \\
0.20 \\
1 \cdot 10\end{array}$ & $\begin{array}{c}2 \cdot 32 \\
1 \cdot 26 \\
1 \cdot 11 \\
19 \cdot 1 \\
7 \cdot 49 \\
0.93 \\
3.04 \\
= \\
= \\
2 \cdot 63 \\
2 \cdot 42 \\
0 \cdot 78 \\
0 \cdot 47\end{array}$ & $\begin{array}{l}0.66 \\
0.94 \\
3.78 \\
2.64 \\
3 \cdot 27 \\
1.35 \\
4.58 \\
- \\
- \\
\overline{3} \cdot 14 \\
1.90 \\
5 \cdot 15\end{array}$ & $\begin{array}{c}4 \cdot 50 \\
15 \cdot 7 \\
1 \cdot 08 \\
4 \cdot 16 \\
8 \cdot 76 \\
0.67 \\
2 \cdot 78 \\
\overline{2} \cdot 75 \\
\overline{14} \cdot 2 \\
2 \cdot 20 \\
2.90\end{array}$ & $\begin{array}{l}0.68 \\
9.46 \\
4.34 \\
5.03 \\
7 \cdot 51 \\
5.03 \\
3.33 \\
\overline{8.30} \\
5.99 \\
1.35\end{array}$ & $\begin{array}{l}9.26 \\
23.0 \\
16.0 \\
7.63 \\
-5.59 \\
5.95 \\
-\quad \\
6.78 \\
\overline{7} .32 \\
1.75 \\
0.94\end{array}$ & $\begin{array}{c}4.81 \\
3.86 \\
15.7 \\
\overline{11} \cdot 1 \\
3.67 \\
4.56 \\
1.91 \\
3.79 \\
2.47\end{array}$ & $\begin{array}{l}9.30 \\
3.55 \\
15.5 \\
-9.53 \\
5.16 \\
5.11 \\
1.67 \\
9.47 \\
4.48\end{array}$ & $\begin{array}{l}1.92 \\
4.05 \\
3.53 \\
6.38 \\
2.78 \\
5.47 \\
5.37 \\
-1.95 \\
1.88 \\
4.82 \\
2.64 \\
2.53\end{array}$ & $\begin{array}{c}6.40 \\
11.4 \\
5.32 \\
11.2 \\
15.5 \\
5.26 \\
3.42 \\
- \\
4.88 \\
2.22 \\
8.90 \\
2.31 \\
1.22\end{array}$ & $\begin{array}{l}3 \cdot 58 \\
\overline{-} \\
5 \cdot 58 \\
\overline{2.50} \\
0 \cdot 49 \\
\overline{9} \\
9 \cdot 23 \\
0.68 \\
1.44 \\
0.81 \\
0.27\end{array}$ & $\begin{array}{l}4.67 \\
0.31 \\
2.10 \\
0.48 \\
1.06 \\
\overline{1.04} \\
0.40 \\
0.91 \\
0.80 \\
0.32\end{array}$ & $\begin{array}{l}0.28 \\
0.38 \\
0.81 \\
\overline{0.30} \\
0.62 \\
\overline{0.32} \\
0.28 \\
0.56 \\
0.96 \\
0.27\end{array}$ & $\begin{array}{l}0.031 \\
0.014 \\
\\
0.028 \\
0.062 \\
0.015\end{array}$ \\
\hline \multicolumn{2}{|c|}{ Mean } & $(\mathrm{mg} / \mathrm{l})$ & & 0.44 & $7 \cdot 28$ & $2 \cdot 46$ & 3.78 & $2 \cdot 74$ & 5.43 & $5 \cdot 10$ & 8.62 & 5.76 & 7.09 & 3.78 & $6 \cdot 50$ & 2.73 & 1.21 & 0.48 & 0.06 \\
\hline
\end{tabular}

$\mathrm{F} \& \mathrm{C}=$ Filling and crimping.

SW $=$ Service waiter.

Loco $=$ Engine driver.

Mon $1=$ Monday preshift.

Mon 2 = postshift.

Saturday and Sunday are non-working days.

*Personal sampling.

†Monday preshift sample after 17 days absence from the factory.

\section{Study 3}

Preshift concentrations of total DNAT on both the Monday mornings of the study were all $<1.3 \mathrm{mg} / 1$ but by the end of the shift the mean (SD) concentration had risen substantially to $7 \cdot 3(8.0) \mathrm{mg} / 1$ (table 3).

For some individuals, total DNAT concentrations in urine decreased rapidly overnight between some consecutive working days, indicating that DNAT was quickly eliminated from the body. Nevertheless, other subjects-31 and 37, for example-consistently showed a higher concentration of DNAT in urine on the morning after exposure. Apparently TNT or its metabolites were retained longer by these individuals since they had among the highest concentrations of DNAT in urine samples taken on a Monday morning after a week's exposure, and also after 17 days away from work.

For the group as a whole the daily mean urinary total DNAT concentrations in preshift samples were lower than those measured in postshift samples. Although the postshift mean concentrations varied during the week, the preshift mean concentrations showed a slight upward trend. Overall, the results demonstrate that individual workers show substantial day to day variations in DNAT concentrations. There is no evidence from the results to suggest that any particular job leads to a substantially higher uptake, although as might be expected, individuals performing service functions, such as fitters, cleaners, and service waiters, tended to have lower concentrations than the rest of the group.

From the limited atmospheric sampling carried out, no significant correlation could be found between the concentrations of TNT detected by personal sampling (taken during the Wednesday shift) and the concentration of total DNAT excreted in urine.

Trace concentrations of DNAT were still found in urine samples taken on a Monday morning 17 days after the last exposure to TNT (table 3). DNAT was still detectable in eight of the nine samples but, with one exception, the concentrations are at least 10 times lower than those found on the two Monday mornings after a working week.

\section{Discussion}

The results show that in all cases a measurable uptake of TNT is taking place in the processes studied. The measurements most directly comparable with ours were made by Hassman who carried out two separate surveys and measured urinary 2,6-DNAT by a polarographic technique and atmospheric concentrations of TNT. ${ }^{1415}$ He showed that mean end of shift and end of week 2,6-DNAT concentrations were $2.5 \mathrm{mg} / 1$ of urine and $6.5 \mathrm{mg} / 1$ (uncorrected) respectively whereas atmospheric concentrations of TNT were within the range $0.6-4.0 \mathrm{mg} / \mathrm{m}^{3}$. In the current surveys mean end of shift and end of week DNAT concentrations (uncorrected) were 9.7 and $10 \mathrm{mg} / \mathrm{l}$, whereas atmospheric TNT concentrations recorded by personal sampling were between 0.1 and 0.7 $\mathrm{mg} / \mathrm{m}^{3}$. These results for urinary DNAT appear higher than Hassman's but the mean values do not differ substantially. One contributory factor, how- 
ever, may be that our results included both DNAT isomers.

The atmospheric monitoring data may be used to estimate potential uptake of TNT through the respiratory route. Using a typical air intake of $9.6 \mathrm{~m}^{3}$ for a workshift, ${ }^{16}$ it is possible to calculate a theoretical maximum DNAT excretion value from absorption of TNT by inhalation. When a calculation of this type is carried out for the process examined in this study it is clear that the actual urinary DNAT concentrations significantly exceed the theoretical maximum value for TNT uptake by inhalation. This result suggests that at least part of the TNT body burden must be acquired by a non-respiratory route. When it is taken into account that not all of the inhaled TNT is likely to be absorbed and the knowledge that only a proportion of TNT is excreted in urine as DNAT, ${ }^{717}$ this conclusion is further reinforced.

Other possible routes of exposure are oral and dermal. Significant absorption by the oral route is thought to be unlikely since washing and showering facilities are provided for use, both before using the canteen and after work. The potential for TNT to be absorbed through the skin has been the subject of some controversy in scientific publications. Early investigators concluded that TNT was readily absorbed through the skin in exposed workers. ${ }^{18} 19$ Subsequently Neal and co-workers carried out experiments in pigs and in people and concluded that TNT is absorbed only slowly through the skin. ${ }^{2021} \mathrm{~A}$ recent review, however, has concluded that skin absorption is a major route for the uptake of TNT" and TNT has been given a "skin notation". by the American Conference of Governmental Occupational Hygienists indicating that they believe that dermal uptake is significant. ${ }^{4}$

It seems probable therefore that skin absorption is a major route of occupational uptake of TNT. Observation of the processes reported here showed that there is a potential for skin exposure at several stages, particularly during the filling operation. Factors such as differing standards of personal hygiene, working practices, and the variable use of protective clothing will affect the degree of uptake and are likely to contribute to the variations in DNAT concentrations observed during a working week.

Whereas results of the second study illustrates that in most cases the peak concentration of DNAT in urine was seen in the postshift samples and that DNAT is rapidly eliminated from the body, study 3 illustrates that this is not true for all subjects. In some cases DNAT concentrations in urine on the morning after exposure were similar to, or higher than, those measured at the end of the previous shift, and this was consistently true for some individuals. This probably reflects interindividual differences in either the rate of uptake, metabolism, or elimination of TNT from the body. A better estimate of the total output of DNAT could have been made if the total DNAT concentration had been determined in 24 hour urine samples.

It is difficult to estimate the degree of absorption of TNT itself from the concentration of DNAT in urine. Two human volunteer studies have been carried out with TNT, both using the oral route. ${ }^{717}$ Whereas these-studies indicate that only a proportion of administered TNT is excreted in urine as DNAT, the metabolic disposition after dermal uptake may not be directly comparable. More reliable and appropriate data are needed about the metabolic disposition of TNT in man if biological threshold limit values are to be set for occupational exposure. In the absence of these data measures have been taken to reduce the degree of absorption of TNT by workers in the explosives factories studied.

We gratefully acknowledge the help of A Sloan and R Armstrong of Nobel's Explosives Company and $\mathrm{C}$ Gore, $\mathrm{K}$ Hughes, and $\mathrm{W}$ Laird of ICI Central Toxicology Laboratory.

\section{References}

${ }^{1}$ Zakhari S, Villaume J, Crain PN. Occupational health and safety aspects of 2,4,6-Trinitrotoluene (TNT). Philadelphia: Franklin Institute, 1978.

${ }^{2}$ Morton AR, Randive MV, Hathway JA. Biological effects of trinitrotoluene from exposure below the threshold limit value. Am Ind Hyg Assoc $J$ 1976;37:56-60.

${ }^{3}$ Hathway JA. TNT: review of dose related effects providing documentation for a workplace standard. J Occup Med 1977; 19:341-5.

${ }^{4}$ American Conference of Governmental Industrial Hygienists. Threshold limit values for chemical substances and physical agents in the work environment. Cincinatti: ACGIH, 1978.

${ }^{5}$ Channon HJ, Mills GT, Williams RT. The metabolism of 2,4,6-trinitrotoluene. Biochem J 1944;38:70-85.

${ }^{6}$ Von Oettingen WF, Donahue DD, Snyder RK, et al. Experimental studies with trinitrotoluene. Public health bulletin 1944;285:78. (US Public Health Service.)

${ }^{7}$ Lemberg R, Callaghan JP. Metabolism of aromatic nitro compounds. Aust J Exp Biol Med Sci 1945;23:1-20.

${ }^{8}$ Snyder RK. Metabolites of 2,4,6-trinitrotoluene (TNT) excreted in the urine of dogs. $J$ Ind Hyg Toxicol 1946;28:59-75.

${ }^{9}$ Webster TA. On the metabolism and excretion of 2,4,6-trinitrotoluene. London: Canston and Sons, 1921. (Medical Research Council. British special report series No 58,49 .)

${ }^{10}$ Snyder RK, von Oettingen WF. A new test for the detection and appraisal of exposure to trinitrotoluene. JAMA 1943;123:203-3.

${ }^{11}$ Almog J, Kraus S, Basch A. Determination of TNT metabolites in urine. Arch Toxicol suppl 1983;6:351-3.

${ }^{12}$ Health and Safety Executive. Guidance note EH40, Occupational Exposure Limits 1984. London: HMSO, 1984.

${ }^{13}$ Boyland E, Manson D, Orr SFD. The biochemistry of aromatic amines 2. The conversion of arylamines to arylsulphamic acids and arylamine- $\mathrm{N}$-glucosiduronic acids. Biochem $J$ 1957;65: 417-23.

${ }^{14}$ Hassman P. Trinitrotoluene. Pracnovni Lekarstvi 1971;23:285-94. 
(In Czech.)

${ }^{15}$ Hassman P. Determination of 2,6-dinitro-4-aminotoluene in the urine of persons exposed to trinitrotoluene. Pracnovni Lekarstvi 1971;23:312-4. (In Czech.)

${ }^{16}$ Coates JE. Lung function: assessment and application to medicine. 4th ed. Oxford: Blackwell Scientific Publications, 1979.

${ }^{17}$ Horecker BL, Snyder RK. IX. Effect of ingestion of small quantities of TNT to humans. Public Health Bulletin 1944;285:50-2. (US Public Health Service.)

${ }^{18}$ Moore B. The causation and prevention of trinitrotoluene (TNT) poisoning. London: Canston and Sons, 1917. (Medical Research Council. British special report series No 11.)

${ }^{19}$ Voegtlin C, Hooper KW, Johnson JM. Trinitrotoluene poisoning, its nature, diagnosis and prevention. $J$ Ind Hyg 1921;3:239-54.

${ }^{20}$ Neal PA, von Oettingen WF, Snyder RK. X. Absorption of TNT through the intact skin of swine. Public health bulletin 1944; 285:53-4. (US Public Health Service.)

${ }^{21}$ Neal PA, von Oettingen WF, Snyder RK. XI. Absorption of TNT through the intact skin of human subjects. Public Health Bulletin 1944;285:55. (US Public Health Service.)

\section{Vancouver style}

All manuscripts submitted to the $\mathrm{Br} J$ Ind Med should conform to the uniform requirements for manuscripts submitted to biomedical journals (known as the Vancouver style).

The $\mathrm{Br} J$ Ind Med, together with many other international biomedical journals, has agreed to accept articles prepared in accordance with the Vancouver style. The style (described in full in $\mathrm{Br}$ Med J, 24 February 1979, p 532) is intended to standardise requirements for authors.

References should be numbered consecutively in the order in which they are first mentioned in the text by Arabic numerals above the line on each occasion the reference is cited (Manson' confirmed other reports ${ }^{2-5} \ldots$. . In future references to papers submitted to the $\mathrm{Br} J$ Ind Med should include: the names of all authors if there are six or less or, if there are more, the first three followed by et al; the title of journal articles or book chapters; the titles of journals abbreviated according to the style of Index Medicus; and the first and final page numbers of the article or chapter.

Examples of common forms of references are:

' International Steering Committee of Medical Editors. Uniform requirements for manuscripts submitted to biomedical journals. Br Med J 1979; 1:532-5.

2 Soter NA, Wasserman SI, Austen KF. Cold urticaria: release into the circulation of histamine and eosinophil chemotactic factor of anaphylaxis during cold challenge. $N$ Engl $J$ Med 1976;294:687-90.

3 Weinstein L, Swartz MN. Pathogenic properties of invading micro-organisms. In: Sodeman WA Jr, Sodeman WA, eds. Pathologic physiology: mechanisms of disease. Philadelphia: W B Saunders, 1974:457-72. 